\title{
Publisher Correction: MEMOTE for standardized genome-scale metabolic model testing
}

Christian Lieven (1), Moritz E. Beber (D), Brett G. Olivier (D), Frank T. Bergmann, Meric Ataman, Parizad Babaei, Jennifer A. Bartell (1), Lars M. Blank, Siddharth Chauhan (1D, Kevin Correia (D), Christian Diener, Andreas Dräger (1), Birgitta E. Ebert, Janaka N. Edirisinghe, José P. Faria, Adam M. Feist (10, Georgios Fengos, Ronan M. T. Fleming (D), Beatriz García-Jiménez, Vassily Hatzimanikatis (1D, Wout van Helvoirt (D), Christopher S. Henry, Henning Hermjakob (D),

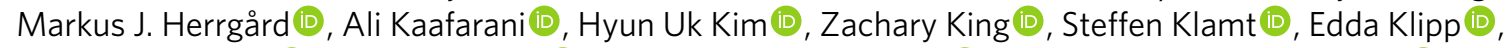

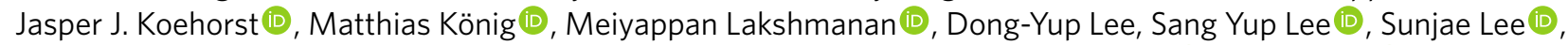
Nathan E. Lewis, Filipe Liu, Hongwu Ma, Daniel Machado, Radhakrishnan Mahadevan (1), Paulo Maia(D, Adil Mardinoglu (D), Gregory L. Medlock, Jonathan M. Monk, Jens Nielsen (1D, Lars Keld Nielsen (1), Juan Nogales (D), Intawat Nookaew, Bernhard O. Palsson (1), Jason A. Papin, Kiran R. Patil (D), Mark Poolman (1D, Nathan D. Price (D, Osbaldo Resendis-Antonio, Anne Richelle, Isabel Rocha, Benjamín J. Sánchez, Peter J. Schaap (D), Rahuman S. Malik Sheriff, Saeed Shoaie (1), Nikolaus Sonnenschein (1), Bas Teusink (1D, Paulo Vilaça, Jon Olav Vik (1), Judith A. H. Wodke, Joana C. Xavier (i), Qianqian Yuan, Maksim Zakhartsev and Cheng Zhang (i)

Correction to: Nature Biotechnology https://doi.org/10.1038/s41587-020-0446-y, published online 2 March 2020.

This paper was originally published under standard Springer Nature copyright (@ The Author(s), under exclusive licence to Springer Nature America, Inc.). It is now available as an open-access paper under a Creative Commons Attribution 4.0 International license. The error has been corrected in the HTML and PDF versions of the article.

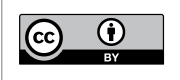

Open Access This article is licensed under a Creative Commons Attribution 4.0 International License, which permits use, sharing, adaptation, distribution and reproduction in any medium or format, as long as you give appropriate credit to the original author(s) and the source, provide a link to the Creative Commons license, and indicate if changes were made. The images or other third party material in this article are included in the article's Creative Commons license, unless indicated otherwise in a credit line to the material. If material is not included in the article's Creative Commons license and your intended use is not permitted by statutory regulation or exceeds the permitted use, you will need to obtain permission directly from the copyright holder. To view a copy of this license, visit http://creativecommons.org/licenses/by/4.0/.

Published online: 19 March 2020

https://doi.org/10.1038/s41587-020-0477-4

(c) The Author(s) 2020 